\title{
People to people diplomacy in a pastoral system: A case from Sudan and South Sudan
}

\author{
Ali Jammaa Abdalla
}

\author{
Correspondence: \\ ali.jammaa@hotmail.com \\ House number 239, 22nd, Tayef \\ City, Khartoum, Sudan
}

\begin{abstract}
Bahr Alarab river, a tributary from the White Nile, forms a natural as well as the political boundary between the two states - Sudan (north) and South Sudan (south) - of the river system. It also represents the natural boundary between the Nilotic tribes of Dinka Malual and Nuer in the south and the Messeriya and Rezaighat Baggara Arab pastoralists (cattle owners) north of the river. This naturally endowed river system, which lies between latitudes $9^{\circ}$ and $10^{\circ} \mathrm{N}$ and $22^{\circ}$ and $32^{\circ} \mathrm{E}$, provided the basis for a symbiotic and peaceful co-existence between these diverse ethnic pastoral groups for more than three decades. The pastoralists, through a well-articulated seasonal migration cycle, managed to successfully share grazing, hunting and fishing areas, in addition to trading and bartering consumer commodities inside what they called 'peace markets'. All these pastoral practices were governed by customary laws enforced by their tribal leaders, through joint tribal courts.

With the separation of the Sudan into two sovereign states - Sudan and South Sudan - in June 2010, new political and security realities emerged, adversely impacting the lives of these pastoral groups. Due to the continuous hostility between the two neighbouring states, the traditional administration which used to monitor the common border was changed into a semi-military structure on both sides.

To circumvent this drastic change of governance and to continue with their mutual relationships, the two communities, the Malual Dinka on one side and Messeriya and Rizaighat on the other, managed to conduct a series of tribal conferences during 2011, culminating in the signing of a joint protocol, stipulating in detail how they should share the natural resources over the river system, regardless of the political changes and hostilities between their two nations. I call this ingenious and pragmatic initiative 'people to people diplomacy in a pastoral system'.
\end{abstract}

Keywords: Malual Dinka, Nilotic tribe, Rizaighat South Darfur tribe, Messeriya South Kordofan tribe, Bahr Alarab river, Peace markets, Comprehensive Peace Agreement

\section{Background and study area}

The two states, Sudan and South Sudan, of what used to be the Sudan until 6 June 2011 share one of the longest political borders in Africa, 1,200 km stretching from the Central African Republic to Ethiopia. The Bahr Alarab river, a tributary of the White Nile in what used to be the Sudan, constitutes, in part $(750 \mathrm{~km})$, a natural boundary between the newly separated states. The area around the border harbours almost all major productive petroleum wells, in addition to millions of cattle. Moreover, the border area also enjoys the availability of surface water (the river) and green pasture throughout the year.

(c) 2013 Abdalla; licensee Springer. This is an Open Access article distributed under the terms of the Creative Commons Attribution License (http://creativecommons.org/licenses/by/2.0), which permits unrestricted use, distribution, and reproduction in any medium, provided the original work is properly cited. 
The border area is inhabited by approximately eight million people. These include, among others, the Nilotic tribes (including Dinka, Nuer and Shilluk) to the south of the river and the Baggara Arab nomads (including those of South Darfur (Rizaighat) and South West Kordofan (Messeriya) on the northern boundary of the river. These communities are cattle owners who practice transhumance seasonally along and around the river system for centuries.

The two pastoral communities under consideration are the Dinka Malual of Northern Bahr Elghazal, in South Sudan, and the Messeriya Arabs of South Western Kordofan, Sudan. The two shared the grazing and water resources along the Bahr Alarab river, which acted as a natural border between them for centuries. The boundary delimited by tribunal is without prejudice to grazing rights. The shared grazing system formula works as follows: Dinka Malual move north to the upper reaches of the Bahr Alarab river into the less swampy dry clay areas during the rainy season from June to October (Cunnison 1966). The Messeriya cattle owners retreat far north of the river system into the sandy areas of Kordofan, avoiding the tsetse fly and other hostile environmental conditions like the muddy clay and flooded and swampy plains during the heavy rains, which their cattle are not accustomed to (Pantuliano et al. 2009). During the dry season, it is the reverse where the Malual retreat deeper into the southern Bahr Elghazal province in what is now South Sudan, leaving ample space for the Messeriya cattle owners who migrate back south from the north to graze the evacuated Malual areas (see Figures 1 and 2). The Malual Dinka move deeper south to more greener and rich pastures, as the youths who were rearing the stock re-join their families who were left behind in their traditional quarters, as part of their labour division between agriculture and animal husbandry.

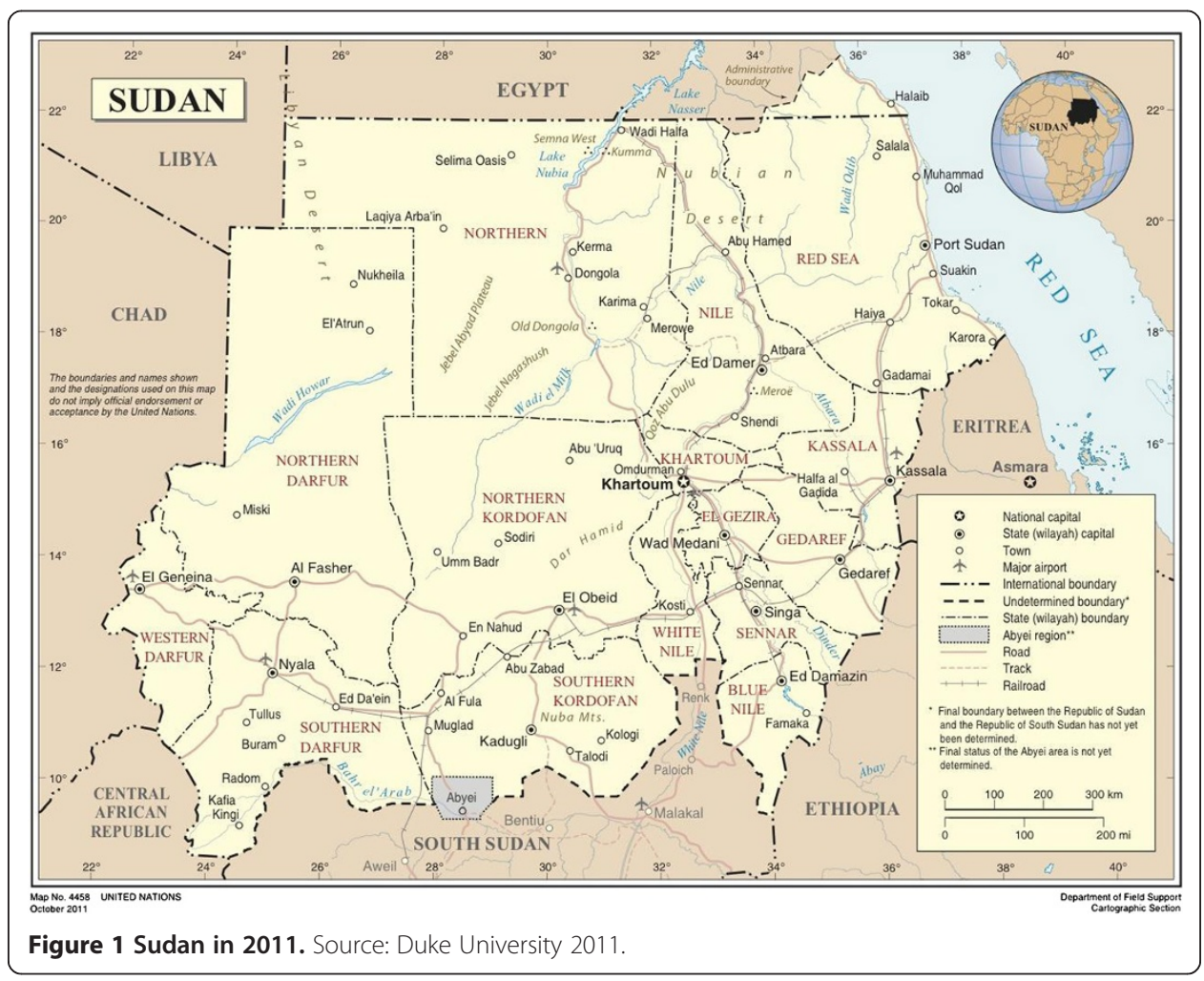




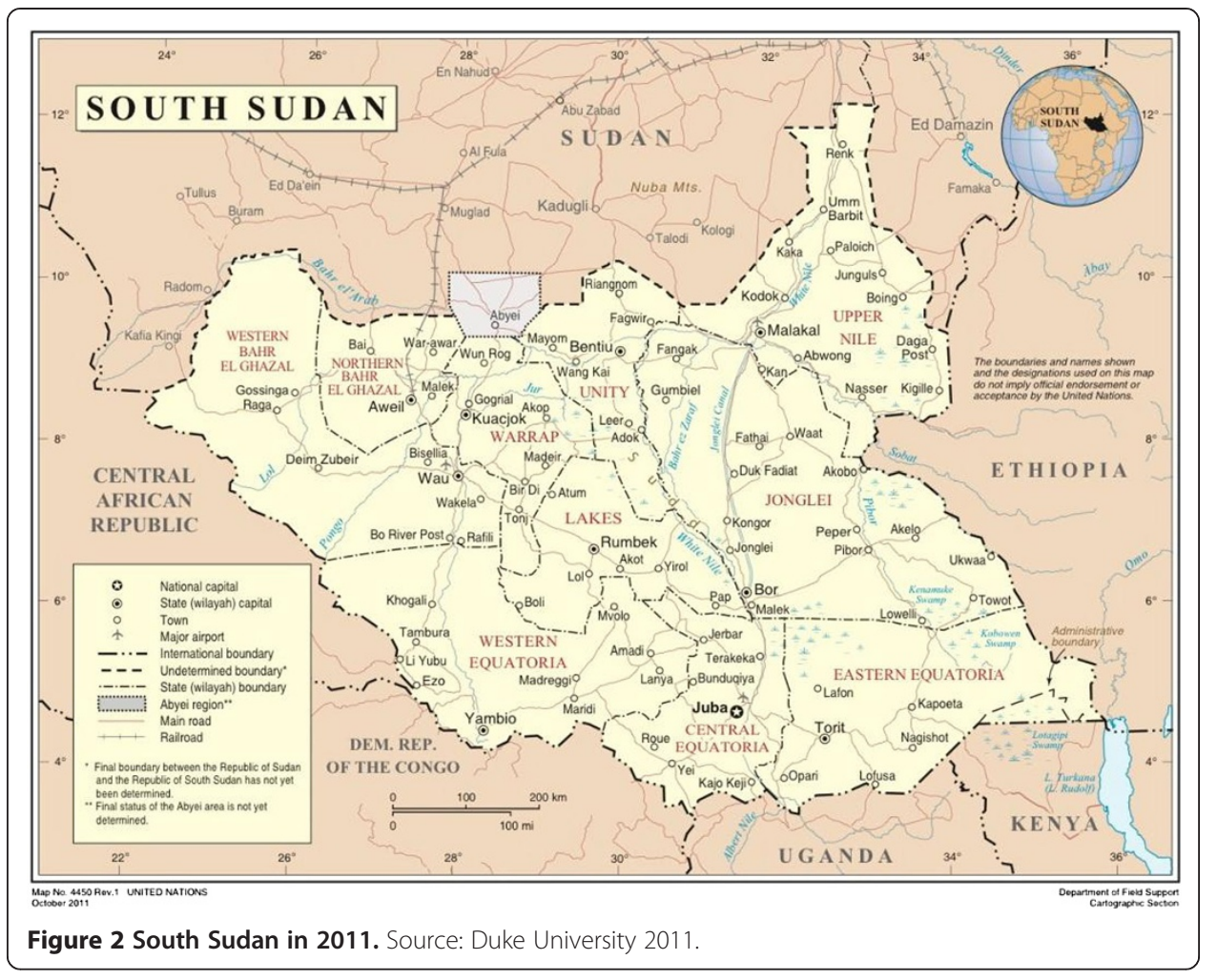

Customary laws and joint tribal courts between these different tribes have existed for more than 200 years to cater for cases pertaining to trespassing over farming lands, theft and abductions which take place from time to time. The settlement of all disputes was arranged and implemented through annual tribal conferences, chaired by tribal chiefs from both sides. The conferences are facilitated by the two governments' administrators along the border since February 2011 when Governor Malong of North Bahr Elghazal Province in South Sudan personally presided over the last conference in Aweil town on 19 March 2011 between the Malual on one side and Messeriya on the other. Almost all current frontline administrators governing the localities along the river from both sides were selected either from retired or active service military personnel. The tribal chiefs, considerably incapacitated, are obviously in the backseat at the moment.

This river system which used to be an administrative boundary between these communities since Sudan's independence in 1956 has changed into an international border after 6 June 2011. The post-separation political changes have dramatically affected the peaceful co-existence between these neighbouring pastoralist communities. Both governments, acting in mutual mistrust, have entrusted the border administration to semi-military officials instead of the traditional native administration systems which used to resolve cross-border problems through customary practices and laws (Tubiana et al. 2012).

This report presents a special case of how the conventional wisdom of two neighbouring pastoral communities has bypassed government politics and squabbling and put building blocks to a lasting peace between themselves, peace that many African states sharing a border have failed to accomplish. 


\section{Responses to the political and constitutional changes of June 2011}

By 6 June 2011, what used to be a $750 \mathrm{~km}$ administrative border between the two neighbouring communities has turned into an international political border - a reality which has proven hard to absorb by the pastoralists across both sides of the divide. On one hand, both governments, due to the mutual hostility and mistrust, wanted all types of relationships and activities to come to a halt. On the other hand, patterns of livelihood across the river could not be expected to change overnight as a consequence of the emerging new political realities.

Understandably, the pastoral communities on both sides of the new border were not ready to tolerate the impact of the political manoeuvring while watching the pattern of their seasonal life cycle and grazing formula slowly deteriorate under the interplay of diverse climatic, environmental, ecological and political factors.

As a result, they decided to act beyond the given administrative and political parameters through what I would call 'People to People diplomacy'. Pastoral leaders, civil society organizations, youth and women all took the lead and suggested holding 'Grassroots Peace conferences', whether the two governments of Sudan and South Sudan agreed or not. Accordingly, brainstorming meetings took place on both sides of the border in mid-February 2012, among the grassroots people and organizations, where many ideas of sustaining the peaceful co-existence were articulated. I had the privilege of facilitating the Messeriya preparatory conference which took place in Almairam town of South Kordofan, during the period 14 and 15 February 2012, and of drafting the 'position paper', which summarized the relevant issues to be discussed with their neighbours, the Dinka Malual. On the South Sudan side, Mr. Achuil, my counterpart, facilitated the Malual Dinka preparatory conference a week earlier in the same month. The joint conference took place in Aweil town on 19 February 2012.

The main recommendations of the Messeriya conference were as follows:

- The historical relationship with Dinka Malual should be maintained, regardless of the government in power. Moreover, it should be formalized by grazing and trade agreements and protocols, given the new political set-up.

- Bearing in mind the deteriorating ecological, environmental and climatic conditions, focus should be on reducing herd numbers and improving quality of cattle. New patterns of sedentary and semi-sedentary models of livestock production should also be encouraged to enable more economically productive and marketable stock, which suits the changing ecology and semi-sedentary life pattern.

- Requests should be made to both governments to relieve the border from any military tensions to allow normal and relaxed community interaction, as both communities can better deal with each other without government intervention.

- Previous agreements of common court laws, traditional administration and customary practices in organizing grazing and access to water and mutual border trade should be revived and promulgated.

- A 'Grassroots Peace Conference' between the two communities should be convened and be presided over by the pastoralists themselves, but civil society organizations, government officials, UN and NGOs are welcome to play a facilitating role. 
The Dinka Malual preparatory conference which was facilitated by my counterpart, Mr. Achuil as facilitator, took place in Aweil, the capital of Northern Bahr Elghazal in South Sudan, four days earlier on 10 February 2012. Similar recommendations were made, including the urgent need for a joint grassroots conference.

Thereafter, the joint grassroots conference took place, under intense and hostile conditions between the two states, in Aweil town from 19 to 21 February 2012. At the end of the conference, a joint communiqué was issued and included the statement, 'We the conferees deplore war and we are committed to end the instability and destruction to our resources resulting in unjustified impediment of development' (see Additional file 1).

The conferees unanimously passed recommendations; the most important of which are as follows:

- Immediate restart of border trade

- Delineation of migration routes during seasonal entry and exit with strict observance to farming plots, water points and agricultural lands

- Disarming of all pastoralists while the two communities intermingle during the dry season

- Joint gender-balanced courts to adjudicate on relevant issues

- Mutual respect and maintenance of peaceful co-existence and protection of rights and peace away from political affiliations

- Youth to have joint sports for peace activities, joint cultural weeks and joint youth committees

- Promotion of intermarriage between the two communities

\section{Sustainability of 'people to people' peace}

As is expected, there are many factors militating against the sustainability of such a people to people peace initiative. Support mechanisms that can contribute to its sustainability could be as follows.

\section{Tribal elites}

The importance of their role cannot be overemphasized. As an example, there was close coordination by Mr. Achuil and myself as facilitators to our respective tribes on both sides. Together, we advocated (through position papers) the common goals and objectives of the preparatory and joint conferences for each community, trying our best to bring consensus to the table.

\section{Civil society organizations and the media}

Pastoralists are almost voiceless at the national level. Their problems are mostly not well perceived by their fellow urban decision makers. Civil society organizations and the media, in addition to parliamentarians from these areas, can form effective platforms to lobby for the voiceless and for such community agreements to be part of the national peace plans.

\section{Employment of ex-combatants on both sides}

Following the Comprehensive Peace Agreement for Sudan, signed in 2005, thousands of ex-combatants on both sides were not absorbed by the disarmament, demobilization 
and re-integration arrangements that followed (Johnson 2011). After a while, they took up arms and became a constant danger to peace, through acts of banditry. They sometimes succeeded in drawing the two communities into wider tribal and sometimes even state conflicts. Providing alternative employment opportunities for the disgruntled excombatants is an important way to safeguarding and sustaining peace.

\section{Revitalization of the 'Peace markets'}

Peace markets are market spots established in optimum locations all along the Bahr Alarab river system. For years they represented an ingenious cross-border trade and commodity exchange model of how neighbouring pastoral communities can protect their interests by circumventing their government's security pressures and surveillance, even during the intensity of war (Behnke 2012).

These markets have developed their own joint access protocols, which were agreed and strictly observed by all pastoralists. The joint tribal administration's courts ensure disarming of all those who attended market days. The protocols also set the rules and regulations through which all beneficiaries should observe and respect each other's religious and tribal codes of conduct. Peace markets, therefore, provide an outstanding example of how the facts of geography remain superior and more sustainable than those of geopolitics, and accordingly should be revitalized.

\section{Establishment of joint cross-border monitoring and follow-up committees}

Implementation and monitoring of access to grazing and other resources has always been observed and enforced by the tribal administration on both sides. This traditional control mechanism which had effectively been exercised for years is no longer effective. The government, in what is now Sudan, had for political reasons deliberately undermined and incapacitated the role and powers of the traditional administration for more than two decades. But, given the track record of tribal administrations in reducing conflict, there should be a room to revive such committees to ensure effective and smooth implementation of the people to people peace protocols.

\section{Conclusion}

Pastoralists across the divide of race, colour, faith and political affiliation behave in an astonishingly rational and pragmatic manner when faced with the hard facts of sharing diminishing resources. Moreover, if left to manage their own resources without external pressure from their respective governments, they are always capable of applying the appropriate formula in terms of natural control mechanisms, which are derived from their own internal practices and social dynamics. However, this requires strong support from both national governments and the international community.

\section{Additional file}

Additional file 1: Dinka Malual and Messeriya Grassroots Peace Conference. 


\section{Authors' information}

AJA is a former UN international staff member who served in several war-torn duty stations like East Timor, Sri Lanka and Iraq as Deputy Resident Representative from 2000 to 2011. Before that, he served as Commissioner of South Kordofan from 1987 to 1989 and Acting Governor of Greater Kordofan from 1985 to 1986 during the last democratic regime. He established the first-ever unit of Pastoral-Nomadic Affairs in Sudan in 1974. His orientation and focus on pastoral affairs stem from his background as a native of a nomadic family from Messeriya of Western Kordofan.

Received: 29 October 2012 Accepted: 11 March 2013

Published: 29 April 2013

\section{References and further reading}

Behnke, R. 2012. The economics of pastoral livestock production and its contribution to the wider economy of Sudan. Feinstein International Center; UNEP. http://sites.tufts.edu/feinstein/files/2012/06/Working-Paper-Econ-of-PastoralLivestock.pdf. Accessed 15 Feb 2013.

Cunnison, IG. 1966. Baggara Arabs: Power and lineage in a Sudanese nomad tribe. Oxford: Clarendon.

Duke University. 2011. Maps of Sudan and South Sudan. http://sites.duke.edu/stefanijones/map-of-the-sudan/ Accessed 15 Feb 2013

Johnson, HF. 2011. Waging peace in Sudan: The inside story of the negotiations that ended Africa's longest civil war. Eastbourne: Sussex Academic Press.

Pantuliano, S, O Egemi, B Fadlalla, M Farah, and ME Abdelgadir. 2009. Put out to pasture: War, oil and the decline of Misseriyya Humr pastoralism in Sudan. Humanitarian Policy Group. London: Overseas Development Institute. http:// www.odi.org.uk/publications/3183-war-oil-sudan-misseriyya-conflict. Accessed 15 February 2013.

Report of the Permanent Court of Arbitration, The Hague. 2009. The Abyei Arbitration: Proceedings of the Permanent Court of Arbitration between the Government of Sudan and The Sudan People's Liberation Movement/Army. The Peace Palace: The Hague July 22nd 2009. Court report.

Tubiana, J, V Tanner, and MA Abdul-Jahlil. 2012. Traditional authorities' peacemaking role in Darfur. United States Institute of Peace, Publication 83, Washington DC. http://www.usip.org. Accessed 15 Feb 2013.

doi:10.1186/2041-7136-3-12

Cite this article as: Abdalla: People to people diplomacy in a pastoral system: A case from Sudan and South

Sudan. Pastoralism: Research, Policy and Practice 2013 3:12

\section{Submit your manuscript to a SpringerOpen ${ }^{\circ}$ journal and benefit from:}

- Convenient online submission

- Rigorous peer review

- Immediate publication on acceptance

- Open access: articles freely available online

- High visibility within the field

- Retaining the copyright to your article

Submit your next manuscript at $\boldsymbol{~ s p r i n g e r o p e n . c o m ~}$ 